\title{
Natural orifice transluminal endoscopic surgery (NOTES) salpingectomy for ectopic pregnancy: a first series demonstrating how a new surgical technique can be applied in a low-resource setting
}

\author{
Van Peer Sarah ${ }^{1} \cdot$ Baekelandt Jan $^{1}$
}

Received: 13 November 2014 / Accepted: 29 June 2015 / Published online: 10 July 2015

(C) Springer-Verlag Berlin Heidelberg 2015

\begin{abstract}
This paper demonstrates the feasibility of a salpingectomy for ectopic pregnancy by transvaginal natural orifice transluminal endoscopic surgery (vNOTES). Conventional, reusable laparoscopic instruments were used and inserted through an inexpensive, self-constructed single port device. The self-constructed single port device was made by assembling a surgical glove, a wound protector, one reusable $10-\mathrm{mm}$ trocar and four reusable 5-mm trocars. We report on five patients who underwent a vNOTES salpingectomy between September 2014 and February 2015. All procedures were successfully performed, without conversion to multiincision laparoscopy or laparotomy. This demonstrates that it is possible to perform a vNOTES salpingectomy without any financial investment in expensive ports, disposable instruments or sealing devices (Video 1). Patient and perioperative data were analysed (Table 1). NOTES salpingectomy is a novel technique requiring further validation. It could be a less invasive alternative to a laparoscopic salpingectomy. A better cosmetic result, by avoiding abdominal incision scars, and less port-related complications, can be expected.
\end{abstract}

Keywords Transvaginal natural orifice transluminal endoscopic surgery (NOTES) · Single port · Frugal innovation · Tubal pregnancy $\cdot$ Salpingectomy $\cdot$ Low resource $\cdot$ vNOTES

Electronic supplementary material The online version of this article (doi:10.1007/s10397-015-0904-6) contains supplementary material, which is available to authorized users.

Baekelandt Jan

jan.baekelandt@imelda.be

1 Department of Obstetrics and Gynaecology, Imelda Hospital Bonheiden, Bonheiden, Belgium

\section{Background}

Over the last 20 years, the advantages of laparoscopy in gynaecological surgery, when compared with open surgery, have been accepted worldwide [1]. Less invasive procedures, such as single incision laparoscopic surgery (SILS) [2] and natural orifice transluminal endoscopic surgery (NOTES) [3-5], are a developing field of minimally invasive surgery. NOTES makes use of the natural orifices of the body as surgical channels of endoscopy; transvaginal access is most frequently used for NOTES. This approach makes use of a single incision to introduce a trocar through which all instruments are inserted.

A better cosmetic result, by avoiding abdominal incision scars, and less port-related complications, for example hernia formation, can be expected.

In this report, we aimed to demonstrate the feasibility of a NOTES salpingectomy using only conventional, reusable laparoscopic instruments and an inexpensive, self-constructed single port device that can be quickly and easily assembled. We aimed to demonstrate that there is no need for expensive, commercially available disposable SILS ports, other disposable instruments or sealing devices to perform a safe and equally time-efficient salpingectomy by NOTES.

\section{Material and methods}

\section{Patients}

Between September 2014 and February 2015, five NOTES salpingectomies were performed for ectopic pregnancy. Ectopic pregnancy was diagnosed based on clinical findings, combined with transvaginal ultrasound and positive serum human chorionic gonadotropin (hCG) level. The NOTES 
salpingectomies were performed as follows (Video 1). The following patient and perioperative data were collected and retrospectively analysed: patient age, body mass index (BMI), total operating time, serum haemoglobin $(\mathrm{Hb})$ drop, (peri-) operative complications and postoperative pain score. The duration of surgery was defined as the time from incision to the end of closure of the colpotomy.

\section{Surgical technique}

The patients were given general anaesthesia and placed in lithotomy position. The lower abdomen and vagina were thoroughly disinfected and draped. A Foley catheter was used to empty the bladder. A $2.5-\mathrm{cm}$ single incision was made in the posterior vaginal fornix. The pouch of Douglas was opened to insert the self-constructed NOTES port. The device was constructed using an Alexis wound protector/retractor (Applied Medical, Rancho Santa Margarita, CA, USA) attached to a size 8 surgical glove (Fig. 1). One finger of the surgical glove was incised to place a $10-\mathrm{mm}$ reusable trocar for $\mathrm{CO}_{2}$ insufflation and laparoscope insertion. Four 5-mm reusable trocars were placed through the other fingers for insertion of the reusable laparoscopic instruments. We used a standard $0^{\circ} 10$ $\mathrm{mm}$ laparoscope. The reusable conventional laparoscopic instruments were a bipolar forceps, a pair of cold scissors, an atraumatic forceps and a suction-irrigation cannula. After placing the patients in Trendelenburg position, $\mathrm{CO}_{2}$ was insufflated to maintain an adequate pneumoperitoneum.

The diagnosis of a tubal pregnancy could be confirmed during the NOTES procedure in all patients, and both ovaries and contralateral tube were normal. The decision was made to perform a salpingectomy, as demonstrated in the video. After complete resection, the salpinx was extracted through the wound protector into the glove part of the self-constructed port. After haemostasis and rinsing of the peritoneal cavity, the pneumoperitoneum was deflated and the port device removed with the salpinx inside it. The vaginal wall was closed using a resorbable running suture.

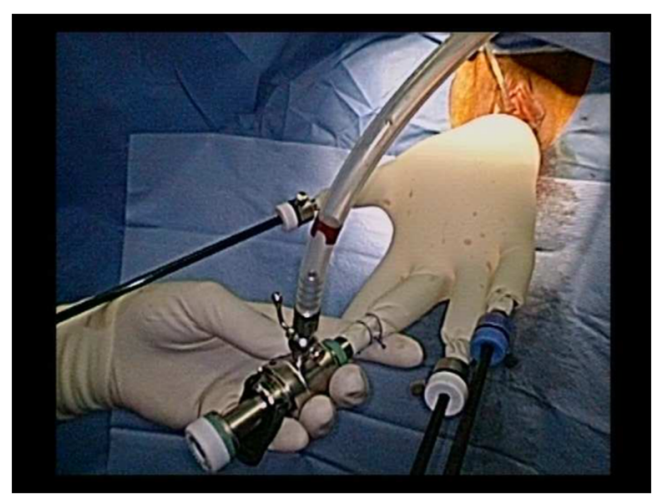

Fig. 1 Conventional, reusable laparoscopic instruments used and inserted through an inexpensive, self-constructed single port device
Parenteral cefazolin and metronidazole were administered preoperatively. As intraoperative analgesia, paracetamol $(1000 \mathrm{mg})$ and ketorolac trometamol $(20 \mathrm{mg})$ were given.

Postoperative pain was assessed using the visual analogue pain scale (VAS) (scoring from 0 - no pain, to 10 -worst imaginable pain).

Postoperative pain was managed by paracetamol $(1000 \mathrm{mg})$ and ketorolac trometamol $(20 \mathrm{mg})$, followed by oral paracetamol.

\section{Results}

Table 1 gives the patient data and operative outcomes. Transvaginal NOTES (vNOTES) for ectopic pregnancy was successfully completed in all patients. No minor or major perior postoperative complications occurred.

The median age of the patients was 29 years (range, 2632). The median body mass index was $23.76 \mathrm{~kg} / \mathrm{m}^{2}$ (range, 19.6-27). Four patients had had one previous delivery, of which one was by Caesarean section and the other three by normal vaginal delivery. For one patient, the ectopic pregnancy was the first pregnancy.

From incision to vaginal closure, the mean operation time was $33 \mathrm{~min}$. The mean blood loss due to the procedure was $36 \mathrm{cc}$. The mean drop in haemoglobin level $24 \mathrm{~h}$ after the operation was $1.96 \mathrm{~g} / \mathrm{dl}$.

In two patients, the ectopic pregnancy ruptured preoperatively causing a haemoperitoneum; in one of these patients, 2 units of packed cells were transfused postoperatively because of a $\mathrm{Hb}$ decrease of $5.4 \mathrm{~g} / \mathrm{dl}$.

The VAS score $12 \mathrm{~h}$ postoperatively was low for all patients, and the median VAS pain scores at $12 \mathrm{~h}$ after surgery were 2 (range 1-2).

\section{Discussion}

Transvaginal laparoscopy was initially reported as a safe and minimally invasive diagnostic technique in infertility [6]. NOTES is an emerging field in gynaecology, gastrointestinal surgery and urology. The first appendectomy via vNOTES was reported on in 2008 [7]. A randomised study on vNOTES cholecystectomy concluded that transvaginal cholecystectomy can be recommended to future patients as an alternative for a laparoscopic cholecystectomy [8]. In urology, pure vNOTES nephrectomy is found to be technically challenging but feasible [9]. In gynaecology, fertility surgeons were the first to start using transvaginal laparoscopy. Transvaginal hydrolaparoscopy is now used as an outpatient procedure for infertility investigation [10]. It can also be used on an ambulatory basis for reconstructive tubo-ovarian surgery [11]. Experienced laparoscopists are now being advised to consider a 
Table 1 Patient characteristics and operative outcomes

\begin{tabular}{|c|c|c|c|c|c|c|c|c|}
\hline Patient & $\begin{array}{l}\text { Age } \\
\text { (years) }\end{array}$ & $\begin{array}{l}\text { BMI } \\
\left(\mathrm{kg} / \mathrm{m}^{2}\right)\end{array}$ & Parity & $\begin{array}{l}\text { Operation } \\
\text { time (min) }\end{array}$ & $\begin{array}{l}\text { Perioperative } \\
\text { findings }\end{array}$ & $\begin{array}{l}\text { Blood loss } \\
\text { Haemoperitoneum } \\
\text { (cc) }\end{array}$ & $\begin{array}{l}\text { Blood loss } \\
\text { Procedure } \\
\text { (cc) }\end{array}$ & $\begin{array}{l}\text { Hb decrease } \\
(\mathrm{g} / \mathrm{dl})\end{array}$ \\
\hline 1 & 28 & 21.5 & 1 (VD) & 30 & $\begin{array}{l}\text { Tubal EP } \\
\text { Ampullary } \\
\text { bleeding }\end{array}$ & 100 & 20 & 1.1 \\
\hline 2 & 27 & 25.5 & $1(\mathrm{CS})$ & 35 & $\begin{array}{l}\text { Tubal EP } \\
\text { Ampullary } \\
\text { bleeding }\end{array}$ & 75 & 20 & 0.7 \\
\hline 3 & 32 & 19.6 & $1(\mathrm{VD})$ & 30 & $\begin{array}{l}\text { Tubal EP } \\
\text { Ruptured }\end{array}$ & 350 & 50 & 1.8 \\
\hline 4 & 26 & 25.2 & 1 (VD) & 50 & $\begin{array}{l}\text { Tubal EP } \\
\text { Ruptured }\end{array}$ & 1400 & 70 & $5.4^{\mathrm{a}}$ \\
\hline 5 & 32 & 27 & 0 & 20 & $\begin{array}{l}\text { Tubal EP } \\
\text { Ampullary } \\
\text { bleeding }\end{array}$ & 100 & 20 & 0.8 \\
\hline
\end{tabular}

${ }^{a} 2 \mathrm{E}$ packed cells transfused

$B M I$ body mass index, $V D$ vaginal delivery, $C S$ Caesarean section, $E P$ ectopic pregnancy

transition towards fertiloscopy in the diagnostic workup of unexplained infertility, or for the purpose of ovarian drilling [12]. vNOTES can also be used as an approach for adnexal surgery and adhaesiolysis [3-5, 13]. A variety of approaches, including the stomach, oesophagus, bladder and rectum, are being used for NOTES procedures. However, the vast majority of NOTES procedures have been performed transvaginally, as the vagina provides direct access [14].

In this report, vNOTES salpingectomy for tubal pregnancy, unruptured or ruptured, was successfully performed using only conventional, reusable laparoscopic instruments and a selfconstructed low-cost NOTES port. The procedures were completed within a reasonable operation time and without complications. No conversion to standard multi-incision laparoscopy or laparotomy was necessary. It was still possible to perform a salpingectomy via vNOTES in a patient with a haemoperitoneum of $1400 \mathrm{ml}$ due to a ruptured ectopic pregnancy. Transvaginal access via a colpotomy was also possible in the two patients who had had no previous vaginal delivery.

Various technical difficulties, such as instrument collision, limited triangulation and reduced tissue traction, are comparable to those for transumbilical SILS and need to be overcome in order to perform vNOTES. These difficulties have been found to be less restricting when compared with SILS, as the colpotomy provides a more flexible entry compared to the infraumbilical fascia opening. Due to camera insertion through the pouch of Douglas, the view through a vNOTES port is opposite to that of a standard laparoscopic view, and this rotation of the surgical field axis required only a brief adaptation period.

Transvaginal NOTES salpingectomy provides a better aesthetic result when compared to a standard laparoscopic salpingectomy as no abdominal incisions are made. Whether patients have less postoperative pain needs to be further assessed in larger studies. A systematic review on vNOTES appendectomies reported a trend towards shorter hospitalisation, quicker recovery, less analgesic requirement and better cosmetic satisfaction [15]. A similar result can be expected for vNOTES salpingectomy. One could argue the possibility of pelvic infection after vaginal surgery, but previous studies have shown that postoperative pelvic infection is unlikely to happen, especially when prophylactic antibiotics are administered $[16,17]$. The risk of dyspareunia due to the colpotomy needs to be taken into account. No difference between conventional compared to laparoscopic transvaginal surgery is to be expected, and different studies show the absence of dyspareunia at a mid- and long-term follow-up [16-18]. Sexual abstinence should be recommended for 6 to 8 weeks as is the recommendation for conventional transvaginal surgery [18].

An inexpensive, self-constructed single port device that can quickly and easily be made by any surgeon was used. Combining this self-constructed port device with easily available, conventional and reusable laparoscopic instruments demonstrates that salpingectomy via vNOTES can be performed without increasing the cost of laparoscopic surgery. This poor man's NOTES technique may potentially be applied in a low-resource setting, where only standard basic laparoscopic equipment is available. Besides being less costly, this approach offers other advantages when compared to commercial ports: it makes use of flexible material that enables greater manipulation of instruments, and a greater number and size of instruments can be passed through the incision. Transvaginal NOTES marks the 
beginning of a new era in the field of endoscopic surgery. NOTES salpingectomy is a novel technique requiring further validation. It could be a less invasive alternative for a laparoscopic salpingectomy.

\section{Compliance with ethical standards}

Funding No funding was received for this study.

Conflict of interest The authors declare that they have no competing interests.

Ethical approval All procedures performed in studies involving human participants were in accordance with the ethical standards of the institutional and/or national research committee and with the 1964 and 1975 Helsinki Declaration and its later amendments (2008 (5)) or comparable ethical standards.

Informed consent was obtained from all patients included in the study.

\section{References}

1. Nieboer TE, Johnson N, Lethaby A et al (2009) Surgical approach to hysterectomy for benign gynaecological disease. Cochrane Database Syst Rev Issue 3. Art No: CD003677. doi:10.1002/ 14651858.CD003677.pub4

2. Yang YS, Oh KY, Hur MH, Kim SY, Yim HS (2015) Laparoendoscopic single-site surgery using conventional laparoscopic instruments and glove porttechnique in gynecology: a single surgeon's experience. J Minim Invasive Gynecol 22(1):87-93. doi: 10.1016/j.jmig.2014.07.013.

3. Lee CL, Wu KY, Su H et al (2012) Transvaginal natural-orifice transluminal endoscopic surgery (NOTES) in adnexal procedures. J Minim Invasive Gynecol 19(4):509-513

4. Yang YS, Hur MH, Oh KY et al (2013) Transvaginal natural orifice transluminal endoscopic surgery for adnexal masses. J Obstet Gynaecol Res 39(12):1604-1609

5. Ahn KH, Song JY, Kim SH et al (2012) Transvaginal single-port natural orifice transluminal endoscopic surgery for benign uterine adnexal pathologies. J Minim Invasive Gynecol 19(5):631-635
6. Gordts S, Campo R, Puttemans P et al (2008) Transvaginal access: a safe technique for tubo-ovarian exploration in infertility? Review of literature. Gynecol Surg 5:187-191

7. Palanivelu C, Rajan PS, Rangarajan M et al (2008) Transvaginal endoscopic appendectomy in humans: a unique approach to NOTES - world's first report. Surg Endosc 22(5):1343-1347

8. Federlein M, Müller VA, Fritze-Büttner F et al (2014) Transvaginal cholecystectomy: results of a randomized study. Chirurg 85(9): $825-832$

9. Xue Y, Zou X, Zhang G et al (2015) Transvaginal natural orifice transluminal endoscopic nephrectomy in a series of 63 cases: stepwise transition from hybrid to pure NOTES. Eur Urol Mar 30. doi: 10.1016/j.eururo.2015.03.033

10. Gordts S, Campo R, Rombauts L, Brosens I (1998) Transvaginal hydrolaparoscopy as an outpatient procedure for infertility investigation. Hum Reprod 13(1):99-103

11. Gordts S, Campo R, Brosens I (2002) Experience with transvaginal hydrolaparoscopy for reconstructive tubo-ovarian surgery. Reprod Biomed Online 4(Supple 3): 72-75

12. Franz M, Ott J, Watrelot A et al (2015) Prospective evaluation of the learning curve of fertiloscopy with and without ovarian drilling. Reprod Biomed Online 30(4):408-414

13. Baekelandt J (2014) Poor man's NOTES: can it be a good approach for adhesiolysis? A first case report with video demonstration. J Minim Invasive Gynecol Nov 10. doi:10.1016/j.jmig.2014.11.001

14. Santos BF, Hungness ES (2011) Natural orifice translumenal endoscopic surgery: progress in humans since white paper. World $\mathrm{J}$ Gastroenterol 17:1655-1665

15. Yagci MA, Kayaalp C (2014) Transvaginal appendectomy: a systematic review. J Minim Invasive Surg 2014:384706. doi:10.1155/ 2014/384706

16. Zornig C, Mofid H, Siemssen L et al (2009) Transvaginal NOTES hybrid cholecystectomy: feasibility results in 68 cases with midterm follow-up. Endoscopy 41:391-394

17. Lee CL, Wu KY, Su H, Wu PJ, Han CM, Yen CF (2014) Hysterectomy by transvaginal natural orifice transluminal endoscopic surgery (NOTES): a series of 137 patients. J Minim Invasive Gynecol 21(5):818-824

18. Tanaka M, Sagawa T, Yamazaki R, Myojo S, Dohi S, Inoue M (2013) Evaluation of transvaginal peritoneal surgery in young female patients. Surg Endosc 27:2619-2624 